\title{
Inpatient child and adolescent psychiatric referrals in Saudi Arabia: clinical profiles and treatment
} F.A. Al-Haidar ${ }^{1}$

$$
\begin{aligned}
& \text { إحالة الأطفال والمراهقين من المرضى الداخليّيّن إلى الطب النفسي في المملكة العربية السعودية: المرتسمات }
\end{aligned}
$$

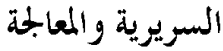

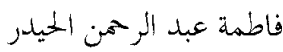

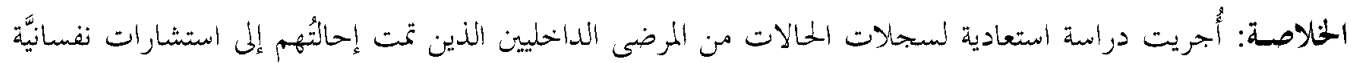

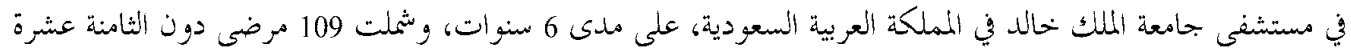

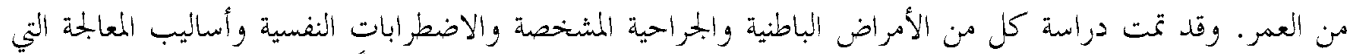

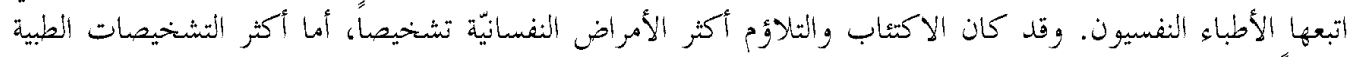

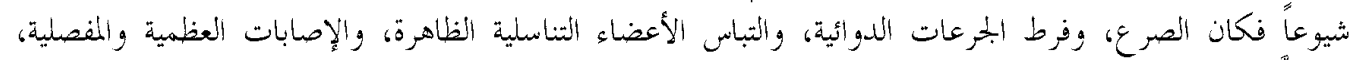

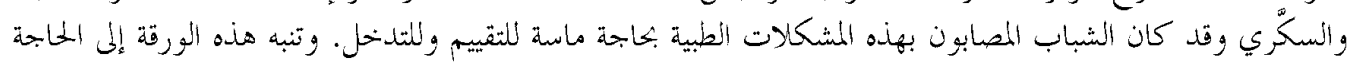

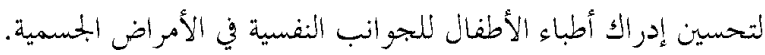

ABSTRACT A retrospective review was made of the case records of inpatients referred to the psychiatric consultation-liaison service of King Khalid University Hospital, Saudi Arabia over a 6-year period. For the 109 patients under 18 years old, the study noted both the medical or surgical diseases diagnosed as well as psychiatric disorders and the treatment approaches used by psychiatrists. Depressive and adjustment disorders were the most often diagnosed psychiatric illnesses. The most common medical diagnoses were epilepsy, drug overdose, ambiguous genitalia, orthopaedic injuries and diabetes mellitus. Young people with these medical problems are in real need of psychological assessment and intervention.

Orientation vers un service psychiatrique des enfants et des adolescents hospitalisés en Arabie saoudite : profils cliniques et traitement

RESUME On a procédé à une analyse rétrospective des dossiers de patients hospitalisés orientés vers le service de consultation-liaison psychiatrique de l'Hôpital universitaire King Khaled (Arabie saoudite) sur une période de six ans. Pour les 109 patients de moins de 18 ans, l'étude a relevé les maladies médicales ou chirurgicales diagnostiquées ainsi que les troubles psychiatriques et les approches thérapeutiques utilisées par les psychiatres. Les troubles dépressifs et les troubles de l'adaptation étaient les troubles psychiatriques les plus fréquemment diagnostiqués. Les diagnostics médicaux les plus fréquemment posés étaient l'épilepsie, la surdose, l'ambiguïté sexuelle, les traumatismes orthopédiques et le diabète sucré. Les jeunes touchés par ces problèmes médicaux ont réellement besoin d'une évaluation psychologique et d'une intervention.

${ }^{1}$ Division of Psychiatry, King Khalid University Hospital, Riyadh, Saudi Arabia. Received: 08/10/02; accepted: 22/04/03

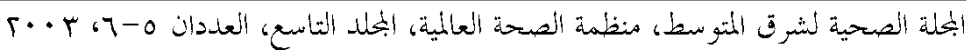




\section{Introduction}

Setting up a psychiatric consultationliaison service in a hospital not only addresses the need for psychological input in medical wards but it may also improve the clinical course of many patients' illnesses by decreasing the length of their hospitalization. As a result, it may also be cost-effective [1-3].

For children, the indications for referral to the psychiatric consultation-liaison services include: obvious disturbances of behaviour and emotions; physical symptoms for which no organic explanation can be found; poor adjustment to chronic or recurrent ill-health; evidence of significant parental or family pathology; known, or suspected, abuse or neglect $[4,5]$.

High psychological disturbance rates have been observed in children admitted to hospital paediatric wards $[1,6,7]$. This is not surprising when medical illnesses in childhood and adolescence, especially when chronic, are increasingly thought to contribute to psychiatric disturbances $[1,4]$. Although emotional problems frequently cause illness in childhood, and can complicate the management of organic diseases [1,8-10], paediatricians often fail to recognize psychiatric disorders [11].

The purpose of this paper was to record what medical diseases were associated with referral of young people to the child and adolescent consultation-liaison psychiatric team in a Saudi Arabian hospital, what psychiatric disorders were found and what treatment approaches were used by the psychiatrist.

\section{Methods}

A retrospective review was made of the case records of all inpatients aged under 18 years who had been referred to the child and adolescent psychiatric consultationliaison team at King Khalid University Hospital. The review covered a period of 6 years between July 1992 and July 1998. King Khalid University Hospital is a teaching general hospital that primarily offers teaching to under- and postgraduate students in different branches of medicine as part of King Saud University. The hospital services cover Riyadh and the surrounding area and are available to all Saudi and nonSaudi Arabians provided they are teaching cases.

A note was made of any medical or surgical diseases diagnosed, psychiatric disorders diagnosed and the drugs and psychotherapeutic approaches used by the psychiatric team. Psychiatric disorders were classified according to the Diagnostic and statistical manual of mental disorders, DSM3R and later DSM4 [12,13].

\section{Results}

A total of 2060 cases were referred to the psychiatric consultation-liaison team: 145 (7.0\%) were below the age of 18 years. Data were not available for 36 patients. Thus 109 cases were included in this study: $46(42.2 \%)$ children under 12 years old and $63(57.8 \%)$ adolescents aged $12-18$ years.

Table 1 shows the medical diagnoses recorded for this group of young people referred to the psychiatrist. The most commonly encountered diagnoses were epilepsy, drug overdose, ambiguous genitalia, orthopaedic injuries and diabetes mellitus. For about $18 \%$ of psychiatric referrals no diagnosed of a medical illness could be found.

Table 2 shows the psychiatric disorders among the referrals. About $29 \%$ of the sample had no psychiatric illness diagnosed. The most common diagnoses were

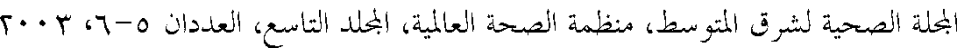


Table 1 Medical profile of 109 inpatients aged under 18 years referred to the psychiatric consultation-liaison team

\begin{tabular}{lrr}
\hline Medical diagnosis & No. & \multicolumn{1}{c}{$\%$} \\
\hline None & 20 & 18.4 \\
Epilepsy & 11 & 10.1 \\
Drug overdose & 11 & 10.1 \\
Ambiguous external genitalia & 8 & 7.3 \\
Orthopaedic injuries & 7 & 6.4 \\
Diabetes mellitus & 7 & 6.4 \\
Non-specific abdominal pain & 4 & 3.7 \\
Non-specific headache & 4 & 3.7 \\
Gastritis & 3 & 2.8 \\
Systemic lupus erythromatosus & 3 & 2.8 \\
Leukaemia & 3 & 2.8 \\
Persistent vomiting & 3 & 2.8 \\
Others & 25 & 22.9 \\
Total & 109 & 100.0 \\
\hline
\end{tabular}

depressive disorder, adjustment disorder, deliberate self-harm and acute organic brain syndrome. A review of the possible psychosocial stressors faced by these patients showed that no stressors could be established for $77 \%$, whereas $12 \%$ suffered family conflicts, $7 \%$ parental divorce or separation, $2 \%$ financial difficulties and $2 \%$ a physically abusive parent.

Table 2 shows the drugs prescribed by the psychiatrists. Over half the young people $(56.0 \%)$ did not receive any psychotropic medication. The most commonly prescribed drugs were antidepressants (23.9\%), followed by anticonvulsants (10.1\%) and antipsychotics (8.3\%). Amitriptyline was the most commonly prescribed antidepressant $(46.0 \%$ of antidepressants), carbamazepine the most prescribed anticonvulsant $(36.4 \%$ of anti- convulsants) and haloperidol the most prescribed antipsychotic (66.7\% of antipsychotics). Methylphenidate was the only central nerrons system stimulant given.

Sixty young people (55.0\%) did not receive any psychotherapy. The most commonly offered therapies were supportive therapy followed by family therapy and then behavioural therapy (Table 2).

Reviewing the records of outpatient follow-up in the child and adolescent psychiatry department showed that $67.0 \%$ of the sample did not have any psychiatric outpatient follow-up while $33.0 \%$ were seen there at least once after discharge from the hospital.

\begin{tabular}{|c|c|c|}
\hline Diagnosis and treatment & No. & $\%$ \\
\hline \multicolumn{3}{|l|}{ Psychiatric diagnosis } \\
\hline None & 32 & 29.4 \\
\hline Depressive disorder & 26 & 23.9 \\
\hline Adjustment disorder & 11 & 10.1 \\
\hline Deliberate self-harm & 7 & 6.4 \\
\hline Acute organic brain syndrome & 6 & 5.5 \\
\hline Conversion disorder & 3 & 2.8 \\
\hline Attention deficit disorder & 3 & 2.8 \\
\hline Others & 21 & 19.3 \\
\hline \multicolumn{3}{|l|}{ Drugs prescribed by psychiatrist } \\
\hline None & 61 & 56.0 \\
\hline Antidepressant & 26 & 23.9 \\
\hline Anticonvulsant & 11 & 10.1 \\
\hline Antipsychotic & 9 & 8.3 \\
\hline CNS stimulant & 2 & 1.8 \\
\hline \multicolumn{3}{|l|}{ Psychotherapy received } \\
\hline None & 60 & 55.1 \\
\hline Supportive therapy & 22 & 20.2 \\
\hline Family therapy & 14 & 12.8 \\
\hline Behavioural therapy & 13 & 11.9 \\
\hline
\end{tabular}

CNS = central nervous system. 


\section{Discussion}

Other studies have consistently noted high rates of psychopathology in children admitted to hospital. For example, Stocking et al. reported that almost two-thirds of children admitted to a paediatric ward would have benefited from consultation with a child psychiatrist [4].

Some studies have found that there is a strong relationship between neurological diseases, particularly epilepsy, and psychiatric disturbance $[14,15]$. In this study, epilepsy formed one-tenth of referrals to the child and adolescent psychiatry team.

Drug overdose for self-poisoning comprised another one-tenth of referrals in this study. An increasing trend of self-poisoning among young people has been recorded in other studies [16,17]. It has been estimated that there are at least 100000 cases of selfpoisoning in the United Kingdom each year; most patients were in their late teens and early twenties, and it was the most common cause of emergency admission to a medical ward for young women [17].

King Khalid University Hospital is a tertiary centre accepting cases of ambiguous genitalia from other hospitals for better medical, surgical and psychological intervention. So it is not surprising that $7.3 \%$ of the sample in this study were referred as cases of ambiguous genitalia. Relational and behavioural difficulties and depressive reactions have been noted in children with ambiguous genitalia who were admitted to hospital for reassignment of sex [18]. They need to be referred to psychiatry for intensive psychotherapy and parental counselling [19].

The next most common category of referral was the $6.4 \%$ of the sample referred to psychiatry from the orthopaedic ward with diagnoses of orthopaedic injuries. A study of children with orthopaedic injuries showed that $41 \%$ had behavioural disturbance and $35 \%$ of parents reported distress in the child that would indicate psychiatric referral [20].

There were also a number of patients with diabetes (6.4\%) referred to the child and adolescent psychiatry team. An association between poor emotional adjustment and poor control of diabetes has long been noted $[14,21]$. The most common psychiatric diagnoses noted among diabetic young people were depression, anxiety and disruptive behaviour [21].

In this study, 3.7\% of young people referred for psychiatry had recurrent abdominal pain and another $3.7 \%$ had non-specific headache. These findings are consistent with the findings of other studies. For example, Campo and Fritch found that medically unexplained physical symptoms are common, including headache, recurrent abdominal pain, limb pain, chest pain and fatigue [22]. Children with recurrent abdominal pain have significantly higher levels of anxiety and depression [23]. Significant association has been found between headache and depression and anxiety disorders [24].

No psychiatric disorders could be confirmed in $29.4 \%$ of children referred. This maybe because the presence of a medically unexplained physical complaint combined with the limited tolerance of paediatric staff to the behavioural problems of some children in an open ward may lead to unwarranted referrals for psychiatric evaluation.

The high rates of depressive disorder (23.9\%) and adjustment disorder (10.1\%) in this study are consistent with the findings of a study from Japan [25]. Nishioka et al. also reported acute organic brain syndrome among $4.9 \%$ of their referred sample, a percentage that is similar to our study (5.5\%) [25].

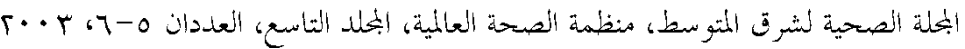


No psychosocial stressors were established for over three-quarters of the children and adolescents referred. This probably reflects inadequate data in the records rather than representing reality. The most reported stressor in this review was family conflicts. However, a wide variety of psychosocial stressors for children have been identified in other studies, including marital conflict, separation or divorce of parents, parental illness or poverty $[5,26]$.

More than half of the young people referred (56.0\%) did not receive any psychotropic medication. This percentage is consistent with the fact that $29.4 \%$ of patients had no psychiatric disturbance diagnosed and the rest had received some sort of psychotherapy that may have satisfied the need of these patients. Antidepressants were the most commonly prescribed drugs, as the largest number of diagnoses were for depression or adjustment disorder.

The psychiatric team did not offer any psychotherapy for $55.1 \%$ of referrals. This is probably because the physical condition of some patients did not allow for immediate psychological intervention or because the paediatric ward was not suitable for conducting some programmes, so they may have been postponed until after discharge. Many of the admitted children (20.2\%) required supportive psychotherapy for better adjustment to the hospital environment. Some of them had chronic illnesses that indicated further need for support. Behavioural therapy was given to $11.9 \%$ of children to modify behavioural disturbances observed in the ward. However, literature reviews show that psychotherapy is not enough and patient and family educational programmes are now regarded as the first stage in the treatment of many chronic or recurrent physical illnesses [27].

Two-thirds of referred patients did not attend a psychiatric outpatient clinic after discharge. This is partly because $29.4 \%$ has no psychiatric illness. In addition, it seems likely that some families are reluctant to bring their child to a psychiatric clinic as they think that their child's problems are medical rather than psychological. Furthermore, some physicians initiate a psychiatric consultation but then are not keen to follow it up.

The results of this study cannot be generalized widely as it is a retrospective study with a small number of patients and it was conducted in a single teaching hospital. However, we conclude that depression and adjustment disorder are commonly encountered in medically ill children and adolescents. Those who are admitted with epilepsy, self-poisoning, orthopaedic injuries and diabetes mellitus are in real need of psychological assessment and intervention. Improving the paediatrician's awareness of psychiatric disorders and the psychological aspects of medical diseases is important.

\section{References}

1. Ortiz P. General principles in child liaison consultation service: a literature review. European child and adolescent psychiatry, 1997, 6:1-6.

2. Gustafsson PA, Svedin CG. Cost effectiveness: family therapy in a pediatric setting. Family systems medicine, 1988, 6:162-75.

3. Thompson TL 2nd. Some advantages of consultation-liaison (medical-surgical) psychiatry becoming an added qualifi- 
cation subspecialty. Psychosomatics, 1993, 34:343-9.

4. Lask B. Paediatric liaison work. In: Rutter M, Taylor E, Herson L, eds. Child and adolescent psychiatry, 3rd ed. Oxford, Blackwell, 1994:996-1005.

5. Knapp PK, Harris ES. Consultation-liaison in child psychiatry: a review of the past 10 years. Part I: Clinical findings. Journal of the American Academy of Child and Adolescent Psychiatry, 1998, 37:17-25.

6. Awad GA, Poznanski EO. Psychiatric consultations in a pediatric hospital. American journal of psychiatry, 1975, 132:915-8.

7. Stocking $M$ et al. Psychopathology in the pediatric hospital-implications for community health. American journal of public health, 1972, 62:551-6.

8. Bingley $L$ et al. The comprehensive management of children in a paediatric ward: a family approach. Archives of disease in childhood, 1980, 55:555-61.

9. Josse JD, Challener J. Liaison psychotherapy in a hospital paediatric diabetic clinic. Archives of disease in childhood, 1987, 62:518-22.

10. Tomm KM, McArthur R, Leahey M. Psychologic management of children with diabetes mellitus. Clinical pediatrics, 1977, 16:1151-5.

11. Guggenheim FG. A marketplace model of consultation psychiatry in the general hospital. American journal of psychiatry, 1978, 135:1380-3.

12. Diagnostic and statistical manual of mental disorders, 3rd ed. revised (DSM IIIR). Washington, USA, American Psychiatric Association, 1987.

13. Diagnostic and statistical manual of mental disorders, 4th ed. (DSM IV). Washington, USA, American Psychiatric Association, 1994.
14. Kaplan H, Sadock BJ, Grebb J. The brain and behaviour. In: Sadock BJ, Sadock VA, eds. Kaplan and Sadock's synopsis of psychiatry, 7th ed. Baltimore, USA, Williams and Wilkins, 1994:87-156.

15. Kaplan H, Sadock BJ, Grebb J. Delirium, dementia, amnesic and other cognitive disorders and mental disorders due to a general medical condition. In: Sadock BJ, Sadock VA, eds. Kaplan and Sadock's synopsis of psychiatry, 7th ed. Baltimore, USA, Williams and Wilkins 1994:336-73.

16. O'Brien JP. Increase in suicide attempts by drug ingestion. The Boston experience, 1964-1974. Archives of general psychiatry, 1977, 34:1165-9.

17. Jones DI. Self-poisoning with drugs: the past 20 years in Sheffield. British medical journal, 1977, 1:28-9.

18. de Carmoy R. Anxiety and reconstructive surgery in children and adolescents [in French]. Psychiatrie de l'enfant, 1995, 38:141-202.

19. Slijper FM et al. Long-term psychological evaluation of intersex children. Archives of sexual behavior, 1998, 27:125-44.

20. Stancin T et al. Acute psychosocial impact of pediatric orthopedic trauma with and without accompanying brain injuries. Journal of trauma, 1998, 45:10318.

21. Liss DS et al. Psychiatric illness and family support in children and adolescents with diabetic ketoacidosis: a controlled study. Journal of the American Academy of Child and Adolescent Psychiatry, 1998, 37:536-44.

22. Campo JV, Fritsch SL. Somatization in children and adolescents. Journal of the American Academy of Child and Adolescent Psychiatry, 1994, 33:1223-35.

23. Leslie SA. Paediatric liaison. Archives of disease in childhood, 1992, 67:1046-9.

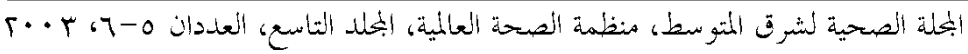


24. Egger HL, Angold A, Costello EJ. Headaches and psychopathology in children and adolescents. Journal of the American Academy of Child and Adolescent Psychiatry, 1998, 37:951-8.

25. Nishioka $Y$, Nishizono M, Yamamoto J. The distribution of mental illness found by DIS (Diagnostic Interview Schedule) among internal and orthopedic patients. Japanese journal of psychiatry and neurology, 1990, 44:33-54.

26. Dulcan MK. The pediatrician as gatekeeper to mental health care for children: do parents' concerns open the gate? Journal of the American Academy of Child and Adolescent Psychiatry, 1990, 29:453-8.

27. Godding V, Kruth M, Jamart J. Joint consultation for high-risk asthmatic children and their families, with pediatrician and child psychiatrist as co-therapists: model and evaluation. Family process, 1997, 36:265-80.

\section{Caring for children and adolescents with mental disorders: Setting WHO directions}

Throughout the history of the WHO Mental Health Programme the attention dedicated to children and adolescents has not been commensurate with that dedicated to adults and the elderly. Yet, from both demographic and epidemiological perspectives - as well as from the burden of disease - mental disorders of children and adolescents represent a key area of concern. Hence WHO convened a meeting on Caring for Children and Adolescents with Mental Disorders: Setting WHO Directions from January 31 and February 1, 2002. The meeting brought together leaders in the care of children and adolescents with mental disorders from around the world. The focus of the meeting was on the care of children and adolescents with mental disorders with special emphasis on emerging issues impacting developing countries. Caring for children and adolescents with mental disorders: Setting WHO directions presents updated information useful for the formulation of a Child and Adolescent Mental Health Care Plan, based on findings which emerged during the above-mentioned meeting, as well as from other sources. The report can be obtained from Marketing and Dissemination, World Health Organization, 20 Avenue Appia, 1211 Geneva 27, Switzerland (tel: +41 22791 2476; fax: +41 22791 4857; email: bookorders@who.int). It is also available free on line at: http:// www.who.int/mental_health/media/en/785.pdf 